\title{
Open Corner Window Shear Wall Structure Stress Influence of Local Component
}

\author{
Liu Taiyu ${ }^{1, a}$, Liu Yanchao ${ }^{2}$, Yang Yue ${ }^{1}$ \\ ${ }^{1}$ School of Civil Engineering, Bowen College of Management Gulin University of Technology, \\ Guilin 541006, China. \\ ${ }^{2}$ PowerChina Real Estate Group LTD,Wuhan 430000, China. \\ a527814253@qq.com
}

Keyword: Shear wall angle window floor slab finite element

\begin{abstract}
In order to satisfy people to the requirement of ventilated daylighting, building shape and vision, residential high-rise shear wall structure are often open corner window in the corner building. But after corner position opening, angle of window will greatly weaken the torsional rigidity of the structure, so that the corner near the component force is much more complicated and more adverse to a seismic. However, the present code of design without the design method about the corner window.Designer for this set of corner window high-rise shear wall structure effect on the stress related to the local structure is largely according to the conceptual design method for design analysis. In this paper, the finite element analysis software MIDAS/GEN of corner window opened for shear wall structure has carried on the example analysis, compared respectively without corner window and corner window landing impact on the stress of the floor, reference for designers.
\end{abstract}

\section{Introduction}

With the rapid development of China's economy, the development of social material life greatly, the land of the city will increasingly become a scarce resource, high-rise building arises at the historic moment.As the widely used forms of high-rise building structure, improvement of the living environment for people, also is the requirement of building plane more diverse. ${ }^{[1]}$ In order to meet the requirements of people on residential vision form ventilated day lighting, opening Angle of window of the shear wall is extensively used in high-rise structures in high-rise building. This kind of structure has better facade better visual effect, at the same time can provide better ventilation and lighting conditions.But the current design specification design method about the corner window In under the action of earthquake, corner window weaken the Angle of structure integrity, so that the corner near the artifacts (floor shear wall fold beam) the stress distribution is more complex, adverse to the structure seismic.Due to the limitations of the existing design analysis software, designers can't place corner window on the shear wall high-rise structure under the action of earthquake loading mechanism has a clear understanding of, so designers can only for concept design for the corner near the window structure, and then according to the partial conservative approach to design.

Many designers through the high-rise shear wall structure in setting up corner window after the structure of the displacement Natural cycles of corner window was analyzed and the influence of the conclusions,but neither affects the component stress simulation analysis. This article use the Building finite element analysis software MIDAS/GEN for corner window high-rise shear wall structure, simulated and analyzed, respectively, compared the opening Angle of window Open not corner window and corner window landing three conditions, it is concluded that the impact on the floor and shear wall stress, reference for designers. ${ }^{[2]}$

\section{The calculation example}

A building for high-rise shear wall structure, corner window set in the four corner, building a total height of 72 meters, a total of 24 layer shear wall thickness is $250 \mathrm{~mm}$, floor thickness is $120 \mathrm{~mm}$, 
concrete strength grade for C30, corner window to the ground, the height is $2300 \mathrm{~mm}$, corner window does not fall to the ground, other window height $1500 \mathrm{~mm} 800 \mathrm{~mm}$ high, Windows 1500 $\mathrm{mm}$ high, gate height is $2300 \mathrm{~mm}$ the structure layout as shown in figure 1. Selected three kinds of solution:

Plan1:Don't open Angle of the window.

Plan2:Open without landing Angle window.

Plan3:The situation of the open ground. ${ }^{[3]}$
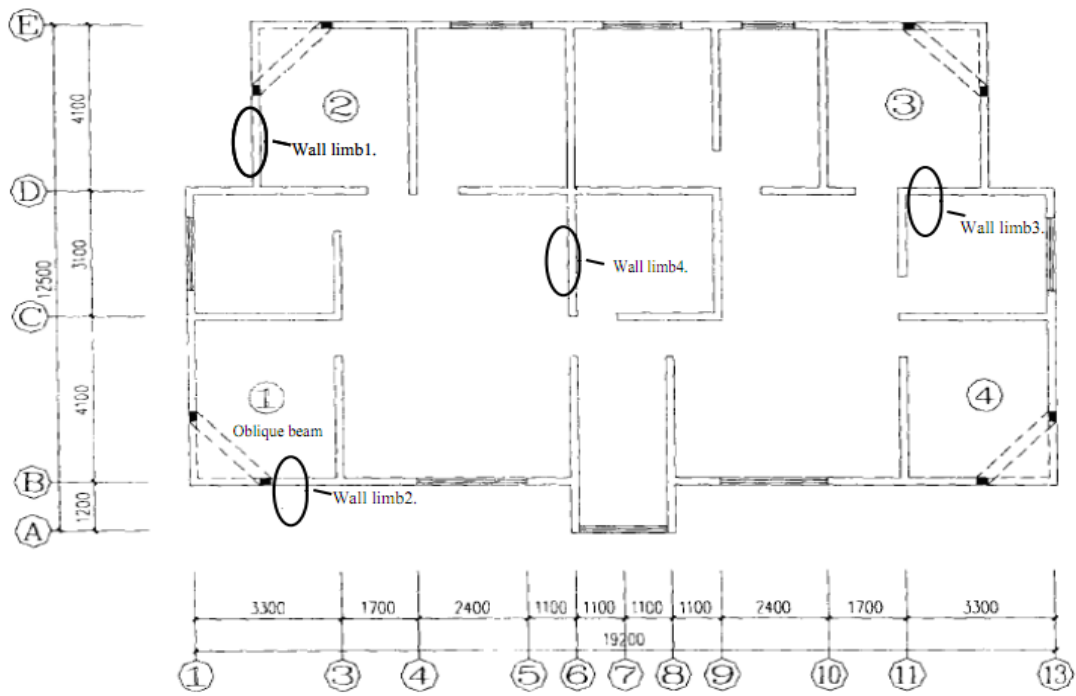

Figure 1 The layout of shear wall

Using MIDAS/GEN structure analysis software of plate unit wall unit and beam element to establish finite element model is shown in figure 2. 2241 units produced a total of 1696 nodes material properties as stipulated in the specification values of modulus of elasticity according to the grade of concrete Gravity load by program automatically.Are used for seismic analysis of building the dynamic time history analysis is of 7 ,in considering the earthquake site characteristic period is 0.40, EL Centro earthquake wave input in vertical and horizontal direction of two component dynamic elastic time history analysis, seismic wave by small earthquakes to consider, the maximum ground acceleration is 0.70 , the ground acceleration time history is shown in figure 3
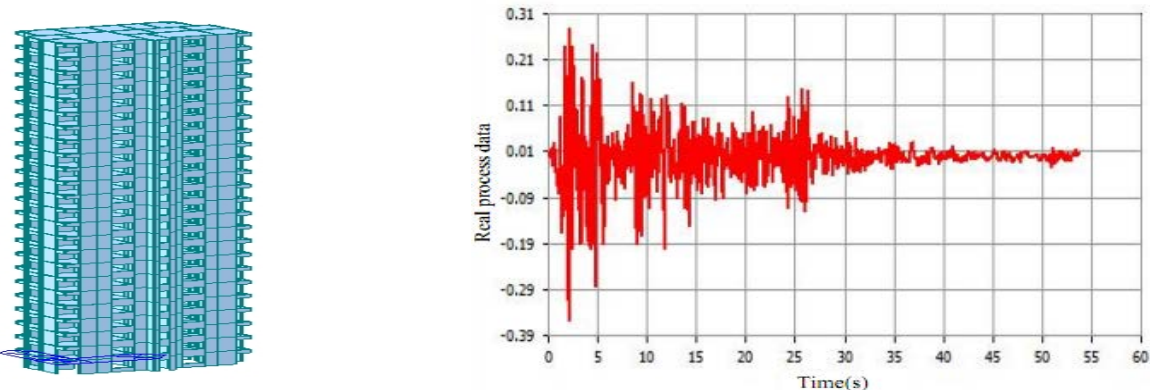

Figure 2. The finite element model Figure 3. The ground acceleration time history 3 . The calculation results and comparison

According to the finite element grid division and the actual load form to calculate the shear wall structure under earthquake load floor and shear wall stress.Figure 4 shown the effective stress for different floor seismic effect.

Table 1 The effective stress of floors located on the wall limb 1（MPa）

\begin{tabular}{ccccccc}
\hline & 3 floors & 6 floors & 10 floors & 15 floors & 20 floors & 24 floors \\
\hline Plan 1 & 1.2719 & 1.3280 & 1.1850 & 0.8777 & 0.4921 & 0.3500 \\
Plan 2 & 1.4974 & 1.4760 & 1.2793 & 0.9170 & 0.4769 & 0.3388 \\
Plan 3 & 1.6184 & 1.6305 & 1.4088 & 1.0033 & 0.5144 & 0.3570 \\
\hline
\end{tabular}


Table 2 The effective stress of floors located on the wall limb2 (MPa)

\begin{tabular}{|c|c|c|c|c|c|c|}
\hline & 3 floors & 6 floors & 10 floors & 15 floors & 20 floors & 24 floors \\
\hline Plan 1 & 1.4517 & 1.7218 & 1.6074 & 1.2778 & 0.7508 & 0.4374 \\
\hline Plan 2 & 1.5193 & 1.8134 & 1.6324 & 1.3028 & 0.7689 & 0.4475 \\
\hline Plan 3 & 1.7028 & 2.0523 & 1.9793 & 1.5838 & 0.9361 & 0.4548 \\
\hline \multicolumn{7}{|c|}{ Table 3 The effective stress of floors located on the wall limb $3(\mathrm{MPa})$} \\
\hline & 3 floors & 6 floors & 10 floors & 15 floors & 20 floors & 24 floors \\
\hline Plan 1 & 1.3006 & 1.4562 & 1.3465 & 1.0531 & 0.5911 & 0.3460 \\
\hline Plan 2 & 1.4261 & 1.5812 & 1.4288 & 1.0784 & 0.6227 & 0.3284 \\
\hline Plan 3 & 1.6453 & 1.7418 & 1.6104 & 1.2344 & 0.7113 & 0.3390 \\
\hline \multicolumn{7}{|c|}{ Table 4 The effective stress of floors located on the wall limb4（MPa） } \\
\hline & 3 floors & 6 floors & 10 floors & 15 floors & 20 floors & 24 floors \\
\hline Plan 1 & 0.9213 & 0.7353 & 0.5084 & 0.3585 & 0.2213 & 0.1535 \\
\hline Plan 2 & 1.1238 & 0.6187 & 0.5665 & 0.3766 & 0.2589 & 0.436 \\
\hline Plan 3 & 1.2152 & 0.8186 & 0.7278 & 0.5374 & 0.2983 & 0.1515 \\
\hline
\end{tabular}
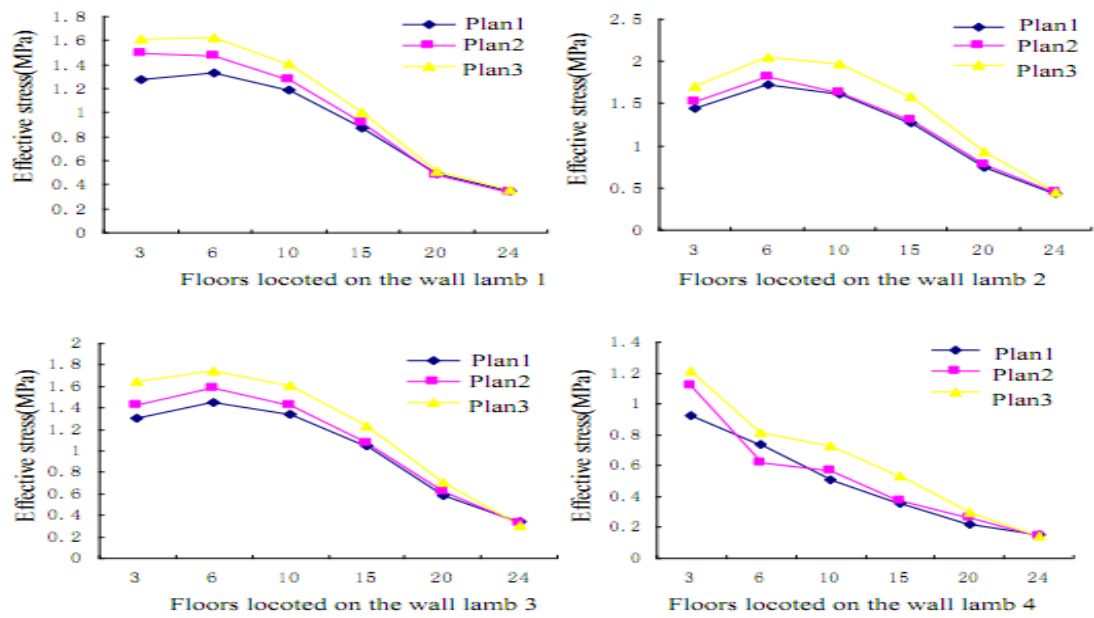

Figure 4 The effective stress for different floors seismic effect

By table 1-4 and figure 4 shows that under the action of earthquake to reverse the floor at different floor window in the corner of the effective stress has increased, and the opening Angle of window size increases, the largest is the 4th floor in 15 of the largest rise in stress, increased $49.9 \%$, however, with the increase of floor, floor increase the effective stress is small Because only choose a direction of seismic wave transmission, so the stress amplitude of the four floor will be different And during an earthquake, the earthquake load transfer to the direction of the buildings is random, so should be with the biggest stress increase.

\section{4 .Conclusion and suggestion}

By comparing the above can be concluded that when building open corner window, floor slab corner window place lack of vertical component constraints, make the floor this level build stress significantly increased, and the stress variation amplitude increase And in the same piece of floor stress gradient increase, increasing the difficulty of design.Especially in the effects of the reverse when the earthquake hit, can make the Angle plate torsion effect strengthen, the stress distribution is more complex When the design, can increase the dark beam slab thickness and increase corner window place to be addressed But that strengthening measures more effective, more economic, needs further research to talk about.

In short, in the design of high-rise shear wall structure with corner window, to analyze the stress of the components problem, strengthen the concept design When the earthquake occurred, the ability to resist torsion of component not too low. 


\section{References}

[1] Feng Zhongwei, Liu Yifeng. Optimization design of tall residential buildings with shear wall structures, Building Structure .[J], 2010,9.

[2]Du Guodong, Ren Jiafu.Research of Angle Window's Influence on High-rise Structure under the Effect of Earthquake [J],2010,6.

[3]Yuteng Yan. research of opening Angle of window high-rise residential shear wall structure [D], Guangxi University,2005. 